\title{
The influence of oral health conditions, socioeconomic status and home environment factors on schoolchildren's self-perception of quality of life
}

Janice S Paula ${ }^{1}$, Isabel CG Leite ${ }^{2}$, Anderso B Almeida², Glaucia MB Ambrosano', Antônio C Pereira ${ }^{1}$ and Fábio L Mialhe ${ }^{1 *}$

\begin{abstract}
Background: The objective this study was to investigate the influence of clinical conditions, socioeconomic status, home environment, subjective perceptions of parents and schoolchildren about general and oral health on schoolchildren's oral health-related quality of life (OHRQoL).

Methods: A sample of 515 schoolchildren, aged 12 years was randomly selected by conglomerate analysis from public and private schools in the city of Juiz de Fora, Brazil. The schoolchildren were clinically examined for presence of caries lesions (DMFT and dmft index), dental trauma, enamel defects, periodontal status (presence/ absence of bleeding), dental treatment and orthodontic treatment needs (DAI). The SiC index was calculated. The participants were asked to complete the Brazilian version of Child Perceptions Questionnaire $\left(\mathrm{CPQ}_{11-14}\right)$ and a questionnaire about home environment. Questions were asked about the presence of general diseases and children's self-perception of their general and oral health status. In addition, a questionnaire was sent to their parents inquiring about their socioeconomic status (family income, parents' education level, home ownership) and perceptions about the general and oral health of their school-aged children. The chi-square test was used for comparisons between proportions. Poisson's regression was used for multivariate analysis with adjustment for variances.
\end{abstract}

Results: Univariate analysis revealed that school type, monthly family income, mother's education, family structure, number of siblings, use of cigarettes, alcohol and drugs in the family, parents' perception of oral health of schoolchildren, schoolchildren's self perception their general and oral health, orthodontic treatment needs were significantly associated with poor OHRQoL $(p<0.001)$. After adjusting for potential confounders, variables were included in a Multivariate Poisson regression. It was found that the variables children's self perception of their oral health status, monthly family income, gender, orthodontic treatment need, mother's education, number of siblings, and household overcrowding showed a strong negative effect on oral health-related quality of life.

Conclusions: It was concluded that the clinical, socioeconomic and home environment factors evaluated exerted a negative impact on the oral health-related quality of life of schoolchildren, demonstrating the importance of health managers addressing all these factors when planning oral health promotion interventions for this population.

\footnotetext{
* Correspondence: mialhe@fop.unicamp.br

'Department of Community Dentistry, Division of Health Education and Health Promotion, Piracicaba Dental School, P.O. BOX 52, University of

Campinas -UNICAMP, 13414-903, Piracicaba, SP, Brazil

Full list of author information is available at the end of the article
} 


\section{Background}

Nowadays, researches point out the need to consider the functional and psychosocial dimensions of oral health for the implementation and evaluation of public health dentistry interventions. In order to achieve these dimensions, instruments that evaluate the oral health-related impact on quality of life (OHRQoL) have been developed [1,2], among them, the Child Perception Questionnaire $\left(\mathrm{CPQ}_{11-14}\right)$ to assess $\mathrm{OHRQoL}$ at a specific age [3].

Several studies focused on children and adolescents have confirmed that oral diseases could have an impact on their quality of life [2,4-9], as caries lesions [10-14] and malocclusion [15-18].

However, a direct relationship between OHRQoL and clinical indicators should be interpreted with caution, because these impacts could be mediated by other factors, such personal, social, and environmental variables [2,19-21].

For example, the socioeconomic status of the household in which the children live may confound the relationships between oral health and OHRQoL $[14,22,23]$. This could occur because several studies have shown associations between low income and poor oral health [8,24-30].

Relative to the home environment, some studies have verified the influence of family on the oral health outcomes of children, considering that their families play a central role in promoting their oral health $[31,32]$. The parental perceptions of their children's oral health conditions may interfere in children's oral health [33]. Other studies have found that parents' socioeconomic characteristics are associated with their subjective perceptions related to their children's oral health status [33,34]. Therefore, the family environment may have an impact on children's self-perception about their OHRQoL, but there is scarcely any information on such association in the literature [14,32].

Although socioeconomic status and family environment could be linked to OHRQoL, this aspect has not yet been sufficiently investigated in studies to evaluate this association in schoolchildren. Only the research developed by Locker et al [22] studied the association between socioeconomic status and family structure on OHRQoL of schoolchildren. The authors verified that children with parents earning a low income, and with only one adult in the household had negative impact in their OHRQoL. In Brazil, only one study [23] evaluated the impact of socioeconomic factors, especially mothers' education, on OHRQoL.

In spite of these evidences, the hypothesis of the present study was that there were many other clinical, socioeconomic and home environment factors that could influence the OHRQoL of children, which have not yet been studied in a statistical regression model.

\section{Purpose}

The objective this study was to investigate the influence of clinical conditions, socioeconomic status, home environment of children and subjective perceptions of parents and children about general and oral health on OHRQoL of schoolchildren.

\section{Methods}

\section{Ethical issues}

Prior to implementation, the research project was submitted to the Ethics Committee of the Piracicaba Dental School, University of Campinas, Brazil, and approved under Protocol 055/2009. Written informed consent was obtained from the participants or parents/guardians of the participants of this study.

\section{Study population}

The present cross-sectional study referred to a representative sample of children from of Juiz de Fora, Brazil. Juiz de Fora is one of the pioneering cities in the industrial state of Minas Gerais, Brazil, and its predominating economic sectors are industry and services. The city has about 570,000 inhabitants, spread over a wide range of socioeconomic backgrounds, of whom $98.91 \%$ have access to fluoridated water [35].

A total of 515 schoolchildren, 12 years of age, were examined according to a random multistage sampling design, which was considered representative of the city. The total number of schoolchildren at the age of 12 years was 7993 [35]. To calculate the probability sample, we adopted a 95\% confidence interval level, 20\% accuracy and design effect (deff) of 2 . The sample size calculation was based on the DMFT (2.3) and standard deviation (2.72) of epidemiological survey previously conducted [36]. The schoolchildren were enrolled in public and private elementary schools and were included in a conglomerate analysis of a population-based study.

\section{Clinical examination}

The schoolchildren were clinically examined at school by two calibrated examiners, in an outdoor setting, under natural light with ball-point probes and mirrors, according to the recommendations of the World Health Organization (WHO) for epidemiological surveys [37]. The examiner calibration process followed the WHO criteria and 20 children were examined in this phase. With regard to the questionnaire, as it has been validated, it was not necessary to conduct a pilot phase to implement them. The examiners were calibrated, and good intra-examiner reproducibility (Kappa > 0.91) was reached.

One examiner collected data with reference to the presence of decayed, missing, and filled teeth in the permanent and primary dentition (DMFT and dmft index). For 
statistical analysis, the presence or absence of untreated caries was evaluated according to the $\mathrm{D}$ component of DMFT index. Dental trauma, enamel defects (DDE index), periodontal status (bleeding) and dental treatment needs were evaluated in exams and categorized according to presence or absence, according WHO recommendations [37].

We used the WHO categorization of treatment needs and subsequently the data were dichotomized: zero, without treatment needs corresponding classification zero of the WHO criteria; and one, with treatment needs classification 1-9 of the WHO criteria [37].

The Significant Caries Index $(\mathrm{SiC})$ was used to measure polarization of the occurrence of caries among participants of the tercile with higher DMF-T. The index was calculated according recommendations of Nishi et al [38].

The other examiner collected data on Malocclusion according the Dental Aesthetic Index (DAI), which assesses the dental appearance by collecting and attributing weight to 10 occlusal traits. The DAI score ranges from 13 (the most socially acceptable) to 100 (the least acceptable), and orthodontic treatment needs can be prioritized based on the predefined categories: having more acceptable dental appearance (score DAI $<31$ - no orthodontic treatment need) or having less acceptable dental appearance (score DAI $\geq 31$ - orthodontic treatment need) [39].

\section{Questionnaires}

Data on the children's gender and the type of school at which they studied were collected. The participants were asked to complete two questionnaires. First, the Brazilian version of the Child Perceptions Questionnaire $\left(\mathrm{CPQ}_{11-14}\right)$, developed by Jokovic et al [3]. This questionnaire was translated and validated for the Brazilian population by Barbosa et al [19] and presents good psychometric properties.

The CPQ ${ }_{11-14}$ is a self-administered instrument used to determine quality of life associated with oral health and consists of 35 items. The responses in each item are given using a Likert-type scale based on the number of points in the scale: "Never" = 0; "Once or twice" = 1; "Sometimes" = 2 ; "Often"= 3; and "Very often" $=4$. Higher scores signify worse OHRQoL.

Secondly, a questionnaire was applied, asking questions about the presence of general diseases, the schoolchildren's self-perception of their general and oral health (excellent/very good/good or fair/poor) and home environment. The variables about home environment were: family structure (children live with both biological parents - yes/no), number of siblings ( 2 and 2 or more), use of cigarettes, alcohol and drugs in the family, and household overcrowding: number of people living in the household for number of rooms $(\leq 1$ person for room or $>1$ person for room) [24].

In addition, a questionnaire was sent to their parents, asking questions about socioeconomic status (monthly family income, parents' educational level, home ownership - yes/no) [40] and their perception about their children's general and oral health. The monthly family income was measured on the basis of the number of minimum wages the family receives (up to $3 / 4$ or more), considering the Brazilian minimum wage at time of data collection of approximately US \$ 290 per month. The parents' educational level was categorized by number of years of schooling into two levels: up to 8 years of schooling or over 8 years.

\section{Statistical analyses}

Data were analyzed using descriptive statistics, univariate analyses, and a regression model. The total score of the CPQ ${ }_{11-14}$ was dichotomized by the median, and represented the dependent variable being analyzed. The chisquare test was used for comparisons between proportions, and evaluated overall associations between the dependent and explanatory variables categorical. Poisson regression was used for multivariate analysis with adjustment for variances (significance of 5\%). The statistical tests were performed using the SAS software [41].

A Poisson regression model was used to assess the association between the predictor variables and outcomes. A backward stepwise procedure was used to include or exclude explanatory variables in the adjustments for the models. Explanatory variables presenting a p value $\leq 0.20$ in the assessment of association to each outcome (univariate analyses) were included in the adjustments for the model. Variables that were not related and did not contribute significantly to the model were eliminated and the final model contained only factors that remained associated at the level $\mathrm{p} \leq 0.05$.

\section{Results}

According to conglomerate sampling, 363 (70.5\%) students from public school and 152 (29.5\%) from private schools participated in the survey. Examinations were carried out in 290 (56.3\%) girls and in 225 (43.7\%) boys. Of the examined participants, caries occurrence was observed in 85 subjects (16.5\%); the mean DMFT was 1.09 (SD 1.70) and dmft was 0.85 (SD 1.42). The SiC index was 3.12.

The prevalence of bleeding was observed in 66 (12.82\%) children and dental trauma in 17 (3.3\%). Enamel defects were present in 81 (15.73\%) participants. DAI scores ranged from 14.98 to 56.46 with a mean of 26.04 (SD 6.48), and 125 (24.3\%) children presented orthodontic treatment needs (DAI $\geq 31$ ). 
The mean CPQ $11-14$ was 23.24 (SD 21.94) and median was 16 , ranging from 0 to 106 . Only 17 (3.3\%) schoolchildren felt no impact on OHRQoL, with $\mathrm{CPQ}_{11-14}$ scores of zero. As regards the children's self-perceptions, 459 (89.1\%) considered their general health excellent, very good or good, and 349 (67.8\%) evaluated oral heath as excellent, very good or good. Two hundred and two participants (42.7\%) had some general diseases.

With regard to home environment, 322 (62.5\%) schoolchildren lived with both biological parents, and 442 (85.8\%) had two or more siblings. The use of cigarettes, alcohol and drugs in the family was related by 229 (44.5\%) participants. The calculation of household overcrowding resulted in 439 (85.2\%) of family living in a house with one or fewer persons per room.

Among parents, 286 completed the questionnaire. As regards socioeconomic status, $242(84.61 \%)$ related 3 or less minimum wages as their monthly family income and 156 (54.5\%) reported home ownership. It was observed that 141 (49.3\%) of children's mothers and 123 (43.35\%) of their fathers had a higher educational level.
With regard to parents' perception, 266 (93\%) considered their children's general health as excellent, very good or good, and 184 (65\%) considered their children's oral health excellent, very good or good.

In Table 1 presents the socioeconomic and home environment variables that showed significant association with a score above the median in the $\mathrm{CPQ}_{11-14}$. In Table 2, associations were observed between clinical conditions and OHRQoL. There was a strong association between orthodontic treatment need and a score above the median in the $\mathrm{CPQ}_{11-}$ ${ }_{14}(\mathrm{p}<0.001)$. The variables DMFT, decayed component (presence of cavitated caries lesion), dental treatment need and presence of bleeding also showed associations with worse OHRQoL $(\mathrm{P}<0.05)$ in the schoolchildren.

The variables that showed no statistically significant difference $(p>0.05)$ were excluded from Tables 1 and 2: parents' perception of children's general health, home ownership, dmft and components, dental trauma, enamel defects and $\mathrm{SiC}$.

All statistically significant variables were included in the Poisson regression model. After adjusting them, it

Table 1 Univariate analysis of association between socioeconomic status and family environment variables with oral health- related quality of life in the overall median scores of $\mathrm{CPQ}_{11-14}(n=515)$

\begin{tabular}{|c|c|c|c|c|c|c|c|}
\hline & \multirow[t]{3}{*}{ Variable } & \multirow[t]{3}{*}{$\mathrm{N}$} & \multirow{2}{*}{\multicolumn{2}{|c|}{$\begin{array}{c}\mathrm{CPQ}_{11-14} \\
\text { Scores }>\text { median }\end{array}$}} & \multicolumn{3}{|c|}{ Prevalence ratio $(\mathrm{PR})$} \\
\hline & & & & & \multirow[t]{2}{*}{ PR crude } & \multirow[t]{2}{*}{$\mathrm{Cl}-95 \%$} & \multirow[t]{2}{*}{$p$} \\
\hline & & & $\mathbf{N}$ & $\%$ & & & \\
\hline \multirow[t]{2}{*}{ Gender } & Female & 290 & 155 & 53.4 & 1.21 & $1.01-1.46$ & 0.0208 \\
\hline & Male & 225 & 99 & 44.0 & 1.00 & & \\
\hline \multirow[t]{2}{*}{ School type } & Public & 363 & 225 & 62.0 & 3.64 & $2.60-5.08$ & $<0.0001$ \\
\hline & Private & 152 & 29 & 19.1 & 1.00 & & \\
\hline \multirow[t]{2}{*}{ Monthly family income } & $\leq 3$ minimum wages & 242 & 143 & 59.1 & 4.33 & $2.04-9.18$ & $<0.0001$ \\
\hline & $>3$ minimum wages & 44 & 6 & 13.6 & 1.00 & & \\
\hline \multirow[t]{2}{*}{ Father's education } & $\leq 8$ years & 124 & 74 & 59.7 & 1.53 & $1.16-2.02$ & 0.0012 \\
\hline & $>8$ years & 108 & 42 & 38.9 & 1.00 & & \\
\hline \multirow[t]{2}{*}{ Mother's education } & $\leq 8$ years & 141 & 94 & 66.7 & 1.82 & $1.42-2.33$ & $<0.0001$ \\
\hline & $>8$ years & 142 & 52 & 36.6 & 1.00 & & \\
\hline \multirow[t]{2}{*}{ Children lives with both biological parents } & No & 193 & 116 & 60.1 & 1.40 & $1.18-1.66$ & 0.0001 \\
\hline & Yes & 322 & 138 & 42.9 & 1.00 & & \\
\hline \multirow[t]{2}{*}{ Number of siblings } & 2 or more & 259 & 157 & 60.6 & 1.60 & 1.33-1.92 & $<0.0001$ \\
\hline & $<2$ & 256 & 97 & 37.9 & 1.00 & & \\
\hline \multirow[t]{2}{*}{ Household overcrowding } & More 1 person/room & 76 & 50 & 65.8 & 1.42 & $1.17-1.71$ & 0.0014 \\
\hline & $\leq 1$ person/room & 439 & 204 & 46.5 & 1.00 & & \\
\hline \multirow[t]{2}{*}{ Cigarettes, alcohol and drug use } & Yes & 229 & 129 & 56.3 & 1.53 & $1.27-1.86$ & $<0.0001$ \\
\hline & No & 286 & 105 & 43.7 & 1.00 & & \\
\hline \multirow[t]{2}{*}{ Parents' perception of children's oral health } & fair/poor & 102 & 72 & 70.6 & 1.69 & $1.37-2.08$ & $<0.0001$ \\
\hline & excellent/very good/good & 184 & 77 & 41.8 & 1.00 & & \\
\hline \multirow[t]{2}{*}{ Children's perception of their general health } & fair/poor & 56 & 42 & 75.0 & 1.62 & $1.36-1.95$ & $<0.0001$ \\
\hline & excellent/very good/good & 459 & 212 & 46.2 & 1.00 & & \\
\hline \multirow[t]{2}{*}{ Children's perception of their oral health } & fair/poor & 166 & 124 & 74.7 & 2.01 & $1.70-2.36$ & $<0.0001$ \\
\hline & excellent/very good/good & 349 & 130 & 37.2 & 1.00 & & \\
\hline \multirow[t]{2}{*}{ General diseases } & Yes & 202 & 114 & 54.4 & 1.26 & $1.06-1.50$ & 0.0061 \\
\hline & No & 313 & 140 & 44.7 & 1.00 & & \\
\hline
\end{tabular}


Table 2 Univariate analysis of association between clinical condition variables and oral health- related quality of life in the overall median of $\mathrm{CPQ}_{11-14}(n=515)$

\begin{tabular}{|c|c|c|c|c|c|c|c|}
\hline & \multirow[t]{3}{*}{ Variable } & \multirow[t]{3}{*}{$n$} & \multirow{2}{*}{\multicolumn{2}{|c|}{$\begin{array}{c}\mathrm{CPQ}_{11-14} \\
\text { scores }>\text { median }\end{array}$}} & \multicolumn{3}{|c|}{ Prevalence ratio (PR) } \\
\hline & & & & & \multirow[t]{2}{*}{ PR crude } & \multirow[t]{2}{*}{$\mathrm{Cl}-95 \%$} & \multirow[t]{2}{*}{$p$} \\
\hline & & & $\mathrm{N}$ & $\%$ & & & \\
\hline \multirow[t]{2}{*}{ DMFT } & $>0$ & 200 & 109 & 54.5 & 1.18 & $0.99-1.41$ & 0.0373 \\
\hline & $<0$ & 315 & 145 & 46.6 & 1.00 & & \\
\hline \multirow[t]{2}{*}{ D (caries lesion) } & Present & 85 & 49 & 57.6 & 1.21 & $0.98-1.49$ & 0.0592 \\
\hline & absence & 430 & 205 & 47.7 & 1.00 & & \\
\hline \multirow[t]{2}{*}{ Dental treatment need } & Yes & 87 & 57 & 65.5 & 1.42 & $1.18-1.71$ & 0.0007 \\
\hline & No & 428 & 197 & 46.0 & 1.00 & & \\
\hline \multirow[t]{2}{*}{ Bleeding } & Yes & 66 & 46 & 69.7 & 1.50 & $1.25-1.82$ & 0.0003 \\
\hline & No & 449 & 208 & 46.3 & 1.00 & & \\
\hline \multirow[t]{2}{*}{ Orthodontic treatment need } & Yes & 125 & 80 & 64.0 & 1.43 & $1.21-1.70$ & 0.0001 \\
\hline & No & 390 & 174 & 44.6 & 1.00 & & \\
\hline
\end{tabular}

was found that children's self perception of their oral health status $(\mathrm{p}<0.0001)$; monthly family income $(\mathrm{p}=$ $0.0001)$; gender, orthodontic treatment need, mother's education ( $\mathrm{p} \leq 0.01$ ); number of siblings, and household overcrowding $(p \leq 0.05)$ showed a strong negative effect on schoolchildren's oral health-related quality of life (Table 3).

\section{Discussion}

Descriptive analysis of the clinical data indicated that the population evaluated in this study had good oral conditions and the average DMFT indicated a better profile when compared within the Brazilian context. Data from the National epidemiological survey realized in 2010 indicated that the DMFT mean for 12-year-old schoolchildren was 2.1 [42], and in the city of Juiz de Fora the DMFT mean was 1.09. The polarization of caries was observed because only $17 \%$ of the participants presented dental treatment needs. The $\mathrm{SiC}$ index (3.12) found was lower than it was in other studies in a 12-year-old population in Brazil [25,28,43,44].

With regard to malocclusion, it was observed that $24.3 \%$ of schoolchildren needed orthodontic treatment. In other studies conducted in Brazil and other countries, using the same malocclusion index, and samples of children of a similar age to those of the present study, prevalence of orthodontic treatment was higher [15-17,45-47]. In the same way as dental caries, malocclusion is a multifactorial disease and various determinants can contribute to its prevalence in different populations [48].

Table 3 Associations among sociodemographic, familiar environment and clinical condition variables with oral healthrelated quality of life in the overall median score of $\mathrm{CPQ}_{11-14}$, through the Poisson model for multiple regression analysis

\begin{tabular}{|c|c|c|c|c|c|c|c|c|}
\hline & \multirow[t]{3}{*}{ Variable } & \multirow[t]{3}{*}{$\mathrm{n}$} & \multirow{2}{*}{\multicolumn{2}{|c|}{$\frac{\mathrm{CPQ}_{11-14}}{\text { scores }>\text { median }}$}} & \multicolumn{4}{|c|}{ Poisson regression } \\
\hline & & & & & \multirow[t]{2}{*}{ Estimative (b) } & \multirow[t]{2}{*}{ SE } & \multirow[t]{2}{*}{ PR - adjusted } & \multirow[t]{2}{*}{$\mathrm{p}$} \\
\hline & & & $\mathbf{N}$ & $\%$ & & & & \\
\hline \multirow[t]{2}{*}{ Children's perception of their oral health } & fair/poor & 166 & 124 & 74.7 & 0.1696 & 0.0371 & 1.18 & $<0.0001$ \\
\hline & excellent/very good/good & 349 & 130 & 37.2 & & & & \\
\hline \multirow[t]{2}{*}{ Monthly family income } & $\leq 3$ minimum wages & 242 & 143 & 59.1 & 0.2015 & 0.0527 & 1.22 & 0.0001 \\
\hline & $>3$ minimum wages & 44 & 6 & 13.6 & & & & \\
\hline \multirow[t]{2}{*}{ Gender } & Female & 290 & 155 & 53.4 & 0.1108 & 0.035 & 1.12 & 0.0015 \\
\hline & Male & 225 & 99 & 44.0 & & & & \\
\hline \multirow[t]{2}{*}{ Orthodontic treatment need } & Yes & 125 & 80 & 64.0 & 0.1183 & 0.0382 & 1.12 & 0.0019 \\
\hline & No & 390 & 174 & 44.6 & & & & \\
\hline \multirow[t]{2}{*}{ Mother's education } & $\leq 8$ years & 141 & 94 & 66.7 & 0.1011 & 0.0393 & 1.11 & 0.01 \\
\hline & $>8$ years & 142 & 52 & 36.6 & & & & \\
\hline \multirow[t]{2}{*}{ Number of siblings } & 2 or more & 259 & 157 & 60.6 & 0.0813 & 0.0377 & 1.08 & 0.0312 \\
\hline & $<2$ & 256 & 97 & 37.9 & & & & \\
\hline \multirow[t]{2}{*}{ Household overcrowding } & More than 1 person/room & 76 & 50 & 65.8 & 0.1056 & 0.0491 & 1.11 & 0.0315 \\
\hline & $\leq 1$ person/room & 439 & 204 & 46.5 & & & & \\
\hline
\end{tabular}


By means of this study it was possible to evaluate the impact of objective and subjective variables, conditions, and socio-environmental status on schoolchildren's OHRQoL. We found an interesting datum: in spite of the sample examined presenting good oral health conditions the majority of participants $(96.7 \%)$ reported some impact on their OHRQoL; that is, $\mathrm{CPQ}_{11-14}$ scores differing from zero. This fact highlights the importance of further studies to investigate other factors that may influence the quality of life of children, which are not related to clinical conditions or dental indicators $[4,9,19,21]$.

According to the univariate analysis, variables such as structure (children living with both biological parents, number of siblings) and family conditions (household overcrowding) have strong influence on schoolchildren's self-perceptions of their oral health. These important data have not yet been investigated in other studies and a hypothesis for this association may be attributed to the relations between home environment (family structure) oral health status and oral health behaviors in children $[9,29,31]$.

Moreover, an association was found between parents' perception about their children's oral health conditions and the OHRQoL perceived by the children $(\mathrm{p}<0.0001)$ in the univariate analysis. These results highlight the influence of family values related to oral health care on children's subjective perceptions about their OHRQoL. Although other studies have verified the influence of family in children's behavior and knowledge in oral health $[14,31-34,49-51]$, this was the first study that indicated the influence of family on children's OHRQoL.

After controlling the confounding variables, the Poisson regression statistical analysis allowed the variables to be adjusted and controlled to define which of them generated the greatest impact on OHRQoL. It was observed that there was a statistically significant association between OHRQoL and the number of siblings and household overcrowding. Nevertheless, it is the first study demonstrating that the number of siblings and household overcrowding were associated with children's OHRQoL. In this respect the present study differs from the others in literature, which associated the number of siblings with tooth brushing $[31,51]$, and household overcrowding with oral health conditions [24].

It was also observed that the monthly family income and mother's education had a strong impact on children's OHRQoL, which was corroborated by the similar results founded by Locker et al [22], in a study conducted in Canada, and Piovesan et al [23] in Brazil.

Children living in families with higher incomes generally present better oral hygiene behaviors, access to health care and preventive interventions, providing them with a better quality of life $[27,33,52]$.
With regard to the clinical variables, in regression analysis, only malocclusion remained as an important oral health characteristic that had a negative impact on the quality of life. This result demonstrated the strong influence exerted by dental esthetic aspects on the schoolchildren's OHRQoL. The literature demonstrates that dentofacial esthetics play an important role in social interaction and psychological well-being [15,17,53-55].

The low prevalence of the other clinical conditions in the children assessed may have contributed to the result no statistically significant found among these clinical conditions and OHRQoL in the Poisson regression. However, the continuous surveillance of dental caries, periodontal status, dental trauma and enamel defects by public health managers is essential for providing a life course perspective involving care, and preventing future dental extractions [56].

Gerritsen et al [57] in a meta-analyses study, found that tooth loss had an impact on the OHRQoL of adults and older adult population. Therefore, public health interventions with the aim of impact on schoolchildren's oral health could present consequences later in life and subsequently, impact on OHRQoL.

With regard to psychological variables, it was found that children who presented a bad self-perception of their oral health showed significant associations with $\mathrm{CPQ}_{11-14}$ scores above the median. According to Barbosa et al [19], the children's self-perception about oral health is one global rating in $\mathrm{CPQ}_{11-14}$, and the association with the overall score of the instrument determined the validity of schoolchildren's responses.

As described, the orthodontic treatment need was the only clinical variable that presented association with OHRQoL outcomes, and its strength of association was less than that of a variety of other personal, social and environmental variables, suggesting that the former was mediated by the others. These results corroborated the importance of the social diagnosis for the planning of health promotion interventions in all social environments in which children live their lives, in order to promote supportive environments for them, in addition to personal skills to maximize the possibility of leading healthy lives and reducing inequalities [22,23,57].

Therefore, it is important to reconsider the current biomedical and restricted paradigm on OHRQOL and to begin to think about the validity of contemporary conceptual models of disease and its consequences, emphasizing the importance of personal, social, and environmental factors in mediating patient-centered quality of life outcomes [58,59].

The data of this research should be interpreted within the context of some limitations. The study had a crosssectional design, which made it difficult to evaluate the 
indicators of risk for OHRQoL. The measures of behavior and self-esteem, which might influence the oral health conditions and subjective perception of the schoolchildren, were not included. Moreover, the evaluation of $\mathrm{CPQ}_{11-14}$ for health domains would be interesting to better define the impacts on quality of life reported by schoolchildren.

\section{Conclusion}

It was concluded that the clinical, socioeconomic and home environment factors evaluated exerted a negative impact in the oral health-related quality of life of schoolchildren, demonstrating the importance of health managers addressing all these factors when planning oral health promotion interventions. We suggest that oral health promotion strategies should involve subjective, social and environmental aspects in planning, action and evaluation. In addition, new longitudinal studies should be conducted to determine causal relationships to OHQoL.

\section{Acknowledgements}

This study was supported by FAPESP (process n 2009/06081-7), São Paulo, Brazil.

\section{Author details}

'Department of Community Dentistry, Division of Health Education and Health Promotion, Piracicaba Dental School, P.O. BOX 52, University of Campinas -UNICAMP, 13414-903, Piracicaba, SP, Brazil. ${ }^{2}$ Department of Public Health, Medicine School, Federal University of Juiz de Fora (UFJF) Juiz de Fora, MG, Brazil.

\section{Authors' contributions}

JSP participated in the conception and design of the study, data interpretation, data acquisition, and drafting the manuscript. ICGL contributed to the conception and design of the study. ABA contributed to the data collection. GMBA participated in data analyses. ACP contributed to critical revision of manuscript. FLM participated in the conception and design of the study and critical revision of manuscript. All authors read and approved the final manuscript.

\section{Competing interests}

The authors declare that they have no competing interests.

Received: 18 February 2011 Accepted: 13 January 2012

Published: 13 January 2012

\section{References}

1. Allen PF: Assessment of oral health related quality of life. Health Qual Life Outcomes 2003, 1:40.

2. Barbosa TS, Gavião MB: Oral health-related quality of life in children: Part II. Effects of clinical oral health status. A systematic review. Int J Dent Hyg 2008, 6:100-107.

3. Jokovic A, Locker D, Stephens M, Kenny D, Tompson B, Guyatt G: Validity and reliability of a measure of child oral health-related quality of life. $J$ Dent Res 2002, 81(7):459-63.

4. Bendo CB, Paiva SM, Torres CS, Oliveira AC, Goursand D, Pordeus IA Vale MP: Association between treated/untreated traumatic dental injuries and impact on quality of life of Brazilian schoolchildren. Health Qual Life Outcomes 2010, 8:114.

5. Brennan DS, Singh KA, Spencer AJ, Roberts-Thomson KF: Positive and negative affect and oral health-related quality of life. Health Quali Life Outcomes 2006, 4:83.
6. Gherunpong S, Tsakos G, Sheiham A: The prevalence and severity of ora impacts on daily performances in Thai primary school children. Health Qual Life Outcomes 2004, 2:57.

7. Jokovic A, Locker D, Guyatt G: Short forms of the Child Perceptions Questionnaire for 11-14-year-old children (CPQ 11-14): Development and initial evaluation. Health Qual Life Outcomes 2006, 4:4.

8. Newton JT, Bower EJ: The social determinants of health: new approaches to conceptualizing and researching complex causal networks. Community Dent Oral Epidemiol 2005, 33:25-34

9. Wilson I B, Cleary PD: Linking clinical variables with health-related quality of life: a conceptual model of patient outcomes. J Am Med Assoc 1995, 273:59-65.

10. Biazevic MGH, Rissotto RR, Michel-Crosato E, Mendes LA, Mendes MOA: Relationship between oral health and its impact on quality of life among adolescents. Braz Oral Res 2008, 22(1):36-42

11. Do LG, Spencer A: Oral Health-Related Quality of Life of children by dental caries and fluorosis experience. J Public Health Dent 2007, 67:132-9.

12. Foster Page LA, Thomson WM, Jokovic A, Locker D: Validation of the Child Perceptions Questionnaire for 11-14 year olds in a population-based study. J Dent Res 2005, 84:649-52.

13. Marshman Z, Rodd H, Stern M, Mitchell C, Locker D, Jokovic A, Robinson PG: An evaluation of the child perceptions questionnaire in the UK. Community Dent Health 2005, 22:151-5.

14. Robinson PG, Nalweyiso N, Busingye J, Whitworth J: Subjective impacts of dental caries and fluorosis in rural Ugandan children. Community Dent Health 2005, 22:231-6.

15. Agou S, Locker D, Streiner DL, Tompson B: Impact of self-esteem on the oral-health-related quality of life of children with malocclusion. Am J Orthod Dentofacial Orthop 2008, 134(4):484-9.

16. Locker D, Jokovic A, Tompson B, Prakash P: Is the Child Perceptions Questionnaire for 11-14 year olds sensitive to clinical and self-perceived variations in orthodontic status? Community Dent Oral Epidemiol 2007, 35:179-85

17. Marques LS, Ramos-Jorge ML, Paiva SM, Pordeus IA: Malocclusion: esthetic impact and quality of life among Brazilian schoolchildren. Am J Orthod Dentofacial Orthop 2005, 129(3):424-27.

18. O'Brien K, Wright JL, Conboy F, Macfarlane T, Mandall N: The child perception questionnaire is valid for malocclusions in the United Kingdom. Am J Orthod Dentofacial Orthop 2006, 129:536-40.

19. Barbosa TS, Tureli MCM, Gavião MBD: Validity and reliability of the Child Perceptions Questionnaires. BMC Oral Health 2009, 9:13.

20. Leão A, Sheiham A: Relation between clinical dental status and subjective impacts on daily living. J Dent Res 1995, 74(7):1408-13.

21. Locker $D$ : Issues in measuring change in self-perceived oral health status. Community Dent Oral Epidemiol 1998, 26:41-7.

22. Locker D: Disparities in oral health-related quality of life in a population of Canadian children. Community Dent Oral Epidemiol 2007, 35:348-56.

23. Piovesan C, Antunes JLF, Guedes RS, Ardenghi TM: Impact of socioeconomic and clinical factors on child oral health-related quality of life. Qual Life Res 2010, 19:1359-66.

24. Antunes JLF, Frazão P, Narvai PC, Bispo CM, Pegoretti T: Spatial analysis to identify differentials in dental needs by area-based measures. Community Dent Oral Epidemiol 2002, 30:133-2.

25. Antunes JLF, Narvai PC, Nugent NZ: Measuring inequalities in the distribution of dental caries. Community Dent Oral Epidemiol 2004, 32:41-8.

26. Christopherson EA, Briskie D, Inglehart MR: Objective, subjective, and self assessment of preadolescent orthodontic treatment need-a function of age, gender, and ethnic/racial background? J Public Health Dent 2009, 69(1):9-17.

27. Locker D, Frosina C, Murray $H$, Wiebe D, Wiebe P: Identifying children with dental care needs: evaluation of a targeted school-based dental screening program. J Pub Health Dent 2004, 64:63-70.

28. Pereira SM, Tagliaferro EPS, Ambrosano GMB, Cortellazzi KL, Meneghim MC, Pereira AC: Dental caries in 12-year-old Schoolchildren and its relationship with socioeconomic and behavioural variables. Oral Health Prev Dent 2007, 5(4):299-306.

29. Petersen PE: Sociobehavioural risk factors in dental caries - international perspectives. Community Dent Oral Epidemiol 2005, 33:274-9.

30. Vanobberge JN, Martens LC, Lesaffre E, Declerck D: Parental occupational status related to dental caries experience in 7-year-old children in Flanders (Belgium). Community Dent Health 2001, 18(4):256-62. 
31. Levin KA, Currie C: Adolescent toothbrushing and the home environment: sociodemographic factors, family relationships and mealtime routines and disorganisation. Community Dent Oral Epidemiol 2010, 38:10-8.

32. Locker D, Jokovic A, Stephens M, Kenny D, Tompson B, Guyatt G: Family impact of child oral and oro-facial conditions. Community Dent Oral Epidemiol 2002, 30:438-48.

33. Talekar BS, Rozier RG, Slade GD, Ennett ST: Parental perceptions of their preschool-aged children's oral health. J Am Dent Assoc 2005, 136(3):364-72.

34. Poutanen R, Lahti S, Sepp囚 L, Tolvanen M, Hausen H: Oral health-related knowledge, attitudes, behavior, and family characteristics among Finnish schoolchildren with and without caries lesions. Acta Odontol Scand 2007, 65:1-10.

35. Brazilian Institute of Geography and Statistics:[http://www.ibge.gov.br/ home/].

36. Brasil: Ministério da Saúde. Projeto SB Brasil 2003. Condições de saúde bucal da população brasileira 2002-2003: resultados principais. Brasília: Departamento de Atenção Básica, Secretaria de Atenção à Saúde, Ministério da Saúde; 2004, [in portuguese].

37. World Health Organization: Oral health surveys: basic methods. Geneva: World Health Organization; 41997.

38. Nishi M, Bratthall D, Stjernswärd J: How to calculate the Significant Caries Index (SiC Index). WHO Collaborating Centre/Faculty of Odontology University of Malmö, Sweden; 2001.

39. Estioko LJ, Wright FA, Morgan MV: Orthodontic treatment need of secondary schoolchildren in Heidelberg, Victoria: an epidemiologic study using the Dental Aesthetic Index. Community Dent Health 1994, 11:147-151.

40. SAS Institute Inc: 8.2: SAS/STAT Guide for personal computers. Cary: SAS Institute; 2001

41. Meneghim MC, Kozlowski FC, Pereira AC, Ambrosano GMB, Meneghim ZMAP: A socioeconomic classification and the discussion related to prevalence of dental caries and dental fluorosis. Cien Saúde Coletiva 2007, 12(2):523-9.

42. Brasil: Ministério da Saúde. Projeto SB Brasil 2010. Condições de saúde bucal da população brasileira: resultados principais. Brasília: Departamento de Atenção Básica, Secretaria de Atenção à Saúde, Ministério da Saúde; 2010, [in portuguese].

43. Cypriano S, Hoffmann RHS, Sousa MLR, Wada RS: Dental caries experience in 12-year-old schoolchildren in southeastern Brazil. J Appl Oral Sci 2008, 16(4):286-92.

44. Peres SHCS, Carvalho FS, Carvalho CP, Bastos JRM, Lauris JRP: Polarization of dental caries in teen-agers in the Southwest of the state of São Paulo, Brazil. Ciência \& Saúde Coletiva 2008, 13(Sup 2):2155-62.

45. Poonacha KS, Deshpande SD, Shigli AL: Dental aesthetic index: applicability in Indian population: a retrospective study. J Indian Soc Pedod Prev Dent 2010, 28(1):13-7.

46. Anosike AN, Sanu OO, da Costa OO: Malocclusion and its impact on quality of life of school children in Nigeria. West Afr J Med 2010 29(6):417-24.

47. Locker D, Quinonez C: To what extent do oral disorders compromise the quality of life? Community Dent Oral Epidemiol 2011, 39:3-11.

48. Thilander B, Pena L, Infante C, Parada SS, Mayorga C: Prevalence of malocclusion and orthodontic treatment need in children and adolescents in Bogota, Colombia. Eur J Orthod 2001, 23:153-167.

49. Jung SH, Tsakos G, Sheiham A, Ryu JI, Watt RG: Socio-economic status and oral health-related behaviours in Koran adolescents. Soc Sci Med 2010, 70:1780-8

50. Ostberg AL, Jarkman K, Lindblad U, Halling A: Adolescents' perceptions of oral health and influencing factors: a qualitative study. Acta Odontol Scand 2002, 60:167-73.

51. Maes $L$, Vereecken $C$, Vanobbergen J: Tooth brushing and social characteristics of families in 32 countries. Int Dent $J$ 2006, 56:159-67.

52. Polk DE, Weyant RJ, Manz MC: Socioeconomic factors in adolescents' oral health: are they mediated by oral hygiene behaviors or preventive interventions? Community Dent Oral Epidemiol 2010, 38:1-9.

53. Feu D, de Oliveira BH, de Oliveira Almeida MA, Kiyak HA, Miguel JA: Oral health-related quality of life and orthodontic treatment seeking. Am J Orthod Dentofacial Orthop 2010, 138(2):152-9.
54. Taylor KR, Kiyak A, Huang GJ, Greenlee GM, Jolley CJ, King GJ: Effects of malocclusion and its treatment on the quality of life of adolescents. Am J Orthod Dentofacial Orthop 2009, 136(3):382-92.

55. Zhang M, McGrath C, Hägg U: Changes in oral health-related quality of life during fixed orthodontic appliance therapy. Am J Orthod Dentofacia Orthop 2008, 133(1):25-9.

56. Sheiham A, Sabbah W: Using universal patterns of caries for planning and evaluating dental care. Caries Res 2010, 44:141-50.

57. Gerritsen AE, Allen PF, Witter DJ, Bronkhorst EM, Creugers NH: Tooth loss and oral health-related quality of life: a systematic review and metaanalysis. Health Qual Life Outcomes 2010, 8:126.

58. Crosby R, Noar SM: What is a planning model? An introduction to PRECEDE-PROCEED. J Public Health Dent 2011, 71(Suppl 1):S7-15.

59. Agou S, Locker D, Muirhead V, Tompson B, Streiner DL: Does psychological well-being influence oral-health-related quality of life reports in children receiving orthodontic treatment? Am J Orthod Dentofacil Orthop 2011, 139(3):369-77.

doi:10.1186/1477-7525-10-6

Cite this article as: Paula et al.: The influence of oral health conditions, socioeconomic status and home environment factors on schoolchildren's self-perception of quality of life. Health and Quality of Life Outcomes 2012 10:6.

\section{Submit your next manuscript to BioMed Central and take full advantage of:}

- Convenient online submission

- Thorough peer review

- No space constraints or color figure charges

- Immediate publication on acceptance

- Inclusion in PubMed, CAS, Scopus and Google Scholar

- Research which is freely available for redistribution

Submit your manuscript at www.biomedcentral.com/submit
C) Biomed Central 